\title{
Erratum to: The ability of the rumen ciliate protozoan Diploplastron affine to digest and ferment starch
}

\author{
K. Wereszka • T. Michałowski
}

Published online: 23 January 2014

(C) Institute of Microbiology, Academy of Sciences of the Czech Republic, v.v.i. 2014

Erratum to: Folia Microbiol (2012) 57:375-377

DOI 10.1007/s12223-012-0146-1

The authors of the paper would like to inform the readers that the reported study was granted by the Polish Ministry of Science and High Education, grant no. NN 311044834 (agreement no. 0448/B/P01/2008/34 between 2008 and 2013).

The online version of the original article can be found at http:// dx.doi.org/10.1007/s12223-012-0146-1.

K. Wereszka $(\triangle) \cdot T$. Michałowski Department of Ruminant Physiology of Nutrition, The Kielanowski Institute of Animal Physiology and Nutrition, Polish Academy of Sciences, Instytucka 3, Jablonna, 05-110 Warsaw, Poland

e-mail: k.wereszka@ifzz.pan.pl 